\title{
Mercado de trabalho do profissional bibliotecário em Goiânia
}

\author{
Maria Auxiliadora Andrade de Echegaray* \\ Adélia Monteiro Barbosa** \\ Maria de Fátima Garbelini*** \\ Tânia Gonzaga Gouveia* ***
}

\section{Resumo}

Este artigo é o relato de aprofundada pesquisa sobre a formação profissional c o mercado de trabalho do bibliotecário de Goiânia. A investigação envolveu profissionais recém-formados, além de empresas e instituiçôes que usam (ou não) serviços de informação. Além do perfil detalhado sobre o mercado, os autores propõcm mudanças no ensino $\mathrm{c}$ na formação do profissional da informação.

Palavras-chave: mercado de trabalho; campo profissional de bibliotccários; ensino.

\section{Introdução}

No momento em que as polêmicas relações universidadeempresa-mercado de trabalho são muito discutidas nos meios acadêmicos, porque ligadas fundamentalmente à noção de cres-

* Bibliotecária, mestre em História, diretora da Faculdade de Comunicação e Biblioteconomia da UFG, coordenadora regional do Grupo CentroOeste da Associação Brasileira de Ensino de Biblioteconomia e Documentação (ABEBD), sócia da Sociedade Brasileira de Estudos Interdisciplinares da Comunicação (INTERCOM) e da Associação Nacional de Pesquisa em Ciência da Informação (ANCIB). E-mail: cizinha@lri.facomb.ufg.br

** Bibliotecária, mestranda em Ciência da Iaformação pela Universidade de Brasília (UnB) e ex-professora da Facomb/UFG.

*** Bibliotecária e professora da Facom/UFG. E-mail: garbelin@bib.facomb.ufg.br

**** Bibliotecária e ex-bolsista de Iniciação Cientifica do PIBIC/ UFG.

Comun. inf., v.1, n. 1, p. 194-211, jan./jun. 1998 
cimento econômico - uma das metas do atual Governo -, a informação passa a ser objeto de especulação não apenas do capital industrial e financeiro, mas a atrair um volume maior de investimentos daquelas parcelas mais esclarecidas dos demais setores produtivos nacionais.

Neste contexto, um fenômeno que não pode deixar de ser mencionado é o da globalização econômica, a "ponta-de-lança" do projeto neoliberal, em curso no mundo, que afeta diretamente os chamados profissionais da comunicação e da informação. Tomando-se como referência a América Latina, é possível dizer que as transações comerciais que se processam no âmbito do Acordo do Cone Sul (Mercosul), por exemplo, exercem pressões significativas sobre a prática desses profissionais, posto que exigem maior rapidez, precisão e eficiência na comunicação de dados e informações.

Este novo cenário acelera o processo de absorção/adoção de novas tecnologias, resultando na criação de unidades de informação mais sofisticadas, até mesmo naquelas áreas identificadas como centros de excelência apenas na atividade agropastoril, como é o caso de Goiás.

O geógrafo Milton Santos desenha, com muita propriedade, um novo mapa do Brasil ao demarcar as áreas onde pontificam ciência, tecnologia e informação. São nestas áreas, denominadas por ele como "meios técnicos-científicos" (Goiânia já foi apontada como uma delas), que os bibliotecários vêem expandir a sua área de atuação. Para o bibliotecário goiano, o problema maior consiste em descobrir a forma correta de explorar essa oportunidade histórica, identificando as necessidades informacionais decorrentes desse processo de modernidade.

Essa nova configuração econômica, que modela todas as relações de produção e a organização social do trabalho, comprometendo a própria cidadania, pressiona a classe bibliotecária a retomar antigos questionamentos políticos e éticos sobre prática profissional e mercado de trabalho, sinalizando para a necessidade de adoção de novos paradigmas.

A análise desse quadro é o desafio que se impôs aos professores e alunos da Universidade Federal de Goiás (UFG) engajados nesta pesquisa, que tem como propósito uma revisão curricular que 


\section{6}

contemple as necessidades do mercado de trabalho, além de estimular a reflexão crítica sobre o verdadeiro papel do profissional bibliotecário na sociedade.

Apesar da profissão de bibliotecário ter o seu exercício regulamentado há mais de trinta e cinco anos (Lei n ${ }^{\circ} 4.084$ de 16/ 08/1962), poucos estudos têm se detido em avaliar a formação e a prática profissionais. Os principais obstáculos para essa análise são apresentados no trabalho de Cysne (1993, p. 15): a ausência de uma proposta para a formação profissional que facilite a elaboração de um currículo e a falta de um consenso sobre o perfil do bibliotecário. Para Mueller (1989, p. 175-176) o perfil profissional é: "o conjunto de conhecimentos, qualidades e competências próprias dos integrantes de uma profissão". No entanto, estes conhecimentos, qualidades e competências precisam ser historicizados, contextualizados. O modelo tecnicista, adotado tradicionalmente pelas escolas de biblioteconomia, tornou-se anacrônico e incapaz de responder às múltiplas exigências da sociedade neste final de século.

É fácil perceber que o atual currículo de biblioteconomia - implantado em 1984 - reproduziu, de uma certa forma, o antigo modelo, uma vez que não apresentou mudanças significativas nos seus núcleos epistemológicos. As matérias foram organizadas de forma linear e as disciplinas, que não levam em conta os requeridos niveis de interdisciplinaridade, acabaram por levar à fragmentação do conhecimento e, por conseqüência, da própria prática profissional. Trata-se de um anacronismo, no momento em que um cast de intelectuais mobiliza-se contra a fragmentação da própria ciência e aposta na emergência de um saber plural construído a partir de uma visão holística da realidade (Echegaray, 1995).

\section{Objetivos}

A pesquisa procurou, a partir dos depoimentos dos bibliotecários que atuam no mercado de trabalho de Goiânia e das instituições oficiais e/ou empresas, potencialmente empregadoras:

- definir o perfil do profissional bibliotecário;

- verificar as áreas de atuação do bibliotecário;

Comun. inf., v.1, n. 1, p. 194-211, jan./jun. 1998 
trabalho;

· identificar possíveis "espaços alternativos" no mercado de

- estabelecer uma relação mais dinâmica entre currículo e mercado;

- verificar os aspectos do currículo que inibem ou facilitam a atuação profissional.

\section{Metodologia}

Foram aplicados dois tipos de questionários: um para os profissionais bibliotecários e outro para as instituições oficiais e/ou empresas. A pesquisa de campo foi realizada no período 1995/ 1996 e contou com a ajuda de uma aluna bolsista de Iniciação Científica. As questões abertas e o discurso informal dos bibliotecários ofereceram pistas para uma análise qualitativa dos dados.

\subsection{Descrição dos grupos estudados}

Foram definidos como universo da pesquisa dois grupos de referência: os bibliotecários que se encontravam no exercício de suas funções, em Goiânia, no período 1995-1996; as instituições públicas (municipais, estaduais e federais) e as empresas (de médio e grande portes) dos setores de indústria, comércio e serviços, potenciais usuárias dos serviços bibliotecários. A amostragem dos bibliotecários correspondeu a um percentual de $42,27 \%$ ( 52 bibliotecários), de um total de 123 bibliotecários. Foram ouvidas 76 empresas e órgãos oficiais $(26,30 \%)$, de um total de 289 . Os questionários foram aplicados in loco, o que permitiu um índice maior de respostas associado à vantagem de se conhecer melhor os sujeitos da pesquisa, dentro de uma perspectiva dialógica.

\section{Discussão e análise dos resultados}

Vale ressaltar que se trata de uma pesquisa em processo, o que significa que algumas análises deverão ser retomadas e aprofundadas. No entanto, já é possível sinalizar com alguns resultados significativos na configuração das relações bibliotecário-mercado de trabalho, em Goiânia. 


\section{1 - Perfil dos bibliotecários}

Observa-se que, embora não se tenha privilegiado os egressos do Curso de Biblioteconomia da UFG, já objeto de uma outra pesquisa em andamento, $71 \%$ dos entrevistados fizeram o seu curso de graduação em Goiânia (Fig. 01).
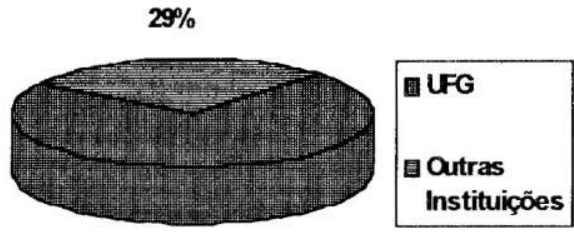

$71 \%$

FIGURA 01 - Instituições de origem dos profissionais bibliotecários de Goiânia.

O baixo indice de qualificação dos bibliotecários entrevistados (Fig. 02) justifica a decisão do Curso de Biblioteconomia de qualificar os seus professores e oferecer, paralelamente, em Goiânia, um curso de pós-graduação stricto sensu, optando pelo Programa de "Mestrado Interinstitucional", implantado recentemente pela CAPES. Observou-se que $84 \%$ dos entrevistados são apenas graduados; $16 \%$, especialistas, incluindo os docentes $(50 \%$ do quadro da UFG) que fizeram parte da amostragem.

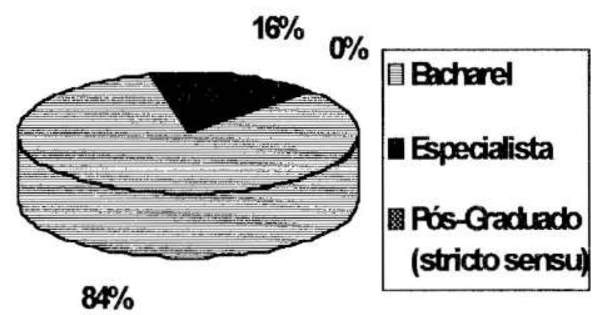

FIGURA 02 - Titulação acadêmica dos profissionais bibliotecários em Goiânia. 
No que se refere aos meios de atualização profissional (Fig. 03), os canais informais - "colégios invisíveis" - são preferidos por $64 \%$ dos bibliotecários entrevistados, seguidos da literatura especializada (15\%) e dos cursos de extensão (13\%). Curiosamente, evidenciou-se um baixo índice de participação em eventos, o que sugere, além do baixo interesse pela educação continuada, a interferência de fatores sócio-econômicos, familiares e de gênero (a maioria dos bibliotecários pertence ao sexo feminino). Recomenda-se maior mobilização da categoria, através da Associação Profissional de Bibliotecários, no sentido de reverter esse quadro. Durante a pesquisa (amostragem randômica) não foi entrevistado nenhum bibliotecário com título de mestre ou doutor.

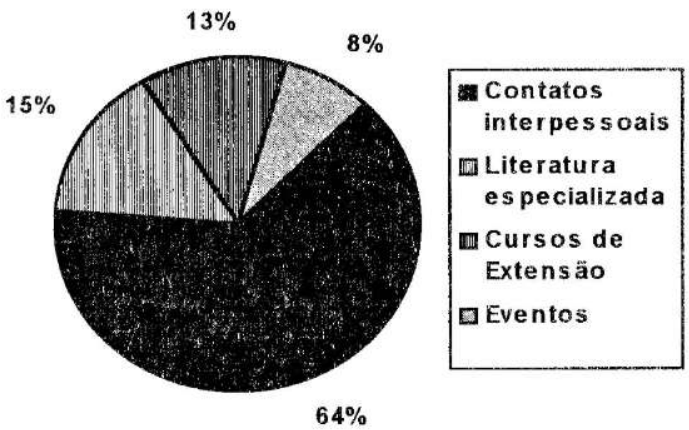

FIGURA 03 - Fontes de atualização do profissional bibliotecário de Goiânia.

Observou-se que o potencial de absorção do bibliotecário pelo mercado de trabalho de Goiânia é alto, uma vez que $84 \%$ dos entrevistados estão atuando na área, mesmo considerando o seu baixo nivel de titulação acadêmica (Fig. 04). Os que estão em desvio ocupacional $(16 \%)$ alegaram baixa remuneração ou sua preferência em atuar em outras áreas.

Comun. inf., v.1, n. 1, p. 194-211, jan./jun. 1998 


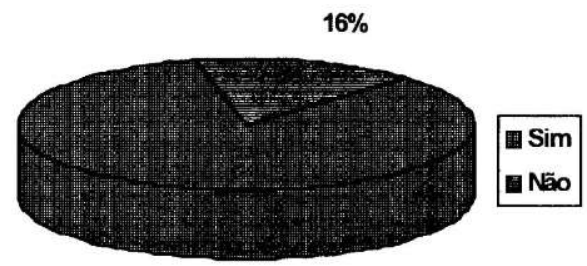

$84 \%$

FIGURA 04 - Absorção do profissional bibliotecário pelo mercado de trabalho de Goiânia.

É interessante observar que a maioria dos bibliotecários de Goiânia $(70 \%)$ trabalha em bibliotecas universitárias e especializadas (Fig. 05). Outros nichos de ocupação são os centros de documentação, arquivos e empresas de consultoria, na razão de $13 \%$. As bibliotecas públicas demonstraram o menor potencial de absorção ( $7 \%$ ), o que indica a falta de politicas consistentes para o setor.

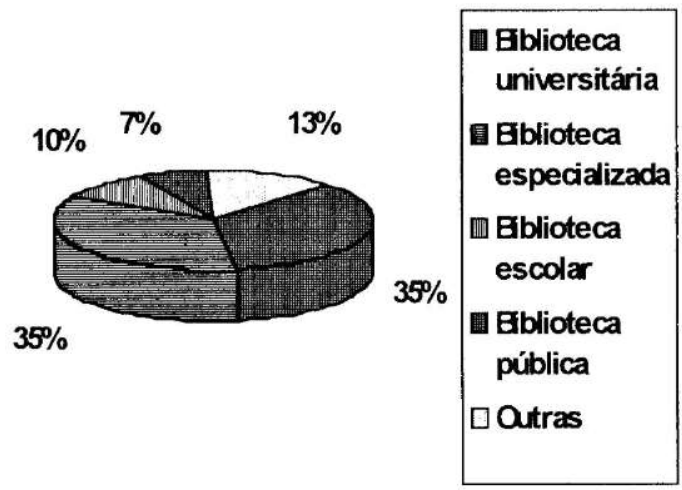

FIGURA 05 - Atuação dos profissionais bibliotecários de Goiânia por tipos de unidades de informação. 
Há uma ênfase significativa das funções técnicas nas atividades desenvolvidas pelos bibliotecários de Goiânia (52\%), o que induz a dois tipos de leituras: formação tecnicista e/ou desconhecimento, por parte dos empregadores, das suas potencialidades nas áreas de gerência e planejamento (Fig 06). Com relação à docência, este índice representa o mais baixo do Brasil (06 professores!).
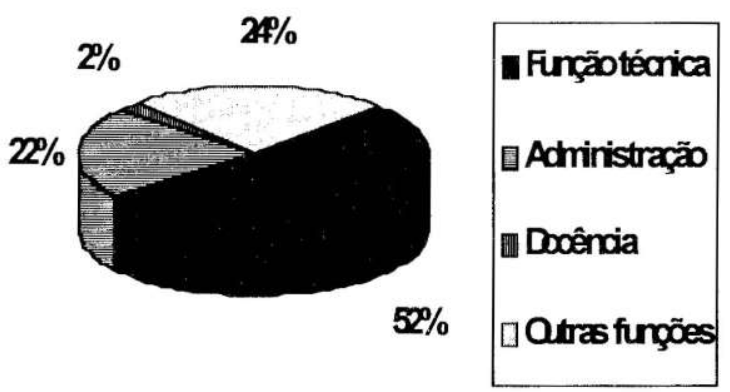

FIGURA 06 - Funções desempenhadas pelos profissionais bibliotecários de Goiânia.

Os bibliotecários entrevistados atribuem à "insuficiência de recursos materiais", especialmente à precariedade das instalações físicas, o maior grau de dificuldade no desempenho de suas funções (31\%). O item "recursos humanos" (escassez e a falta de qualificação) merece o segundo destaque, atingindo o percentual de $23 \%$, o que revela distorções na formação do bibliotecário - a não priorização da educação continuada. A falta de apoio da administração superior atingiu o percentual de $20 \%$. Entre as dificuldades apontadas dentro do item "desatualização profissional", destacam-se o desconhecimento de linguas e a falta de domínio em áreas específicas (Fig. 07). 

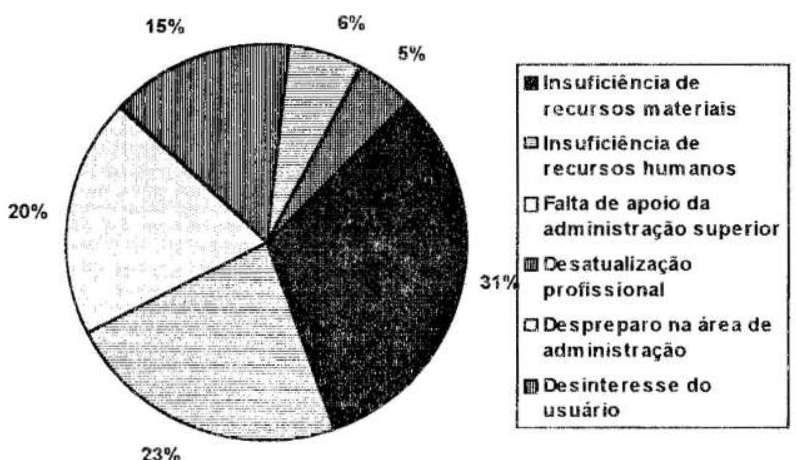

FIGURA 07 - Dificuldades do profissional bibliotecário de Goiânia no exercício de suas funções.

\section{2 - Perfil das instituições c/ou empresas}

Das instituições e/ou empresas sorteadas para a amostragem, $42 \%$ pertencem ao setor privado; $40 \%$ referem-se às instituições públicas - municipais, estaduais e federais - (Fig. 08).
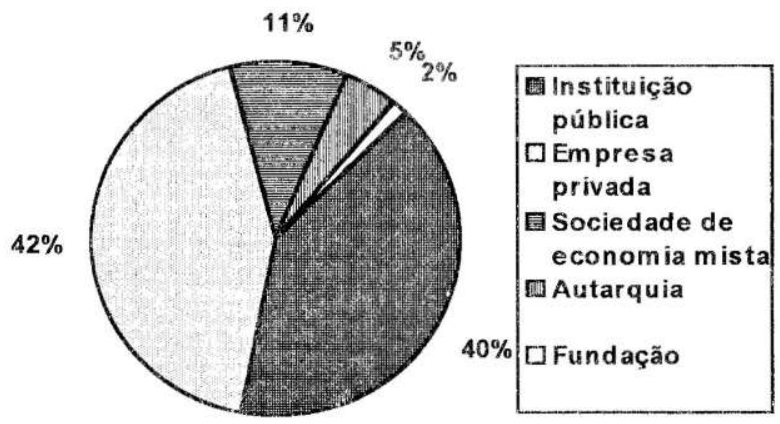

FIGURA 08 - Caracterização das instituições e/ou empresas de Goiânia.

Comun. inf., v.1, n. 1, p. 194-211, jan.jun. 1998 
A pesquisa mostrou que $52 \%$ das instituições e/ou empresas de Goiânia não possuem unidades de informação (Fig. 09), o que sinaliza para a potencialidade do mercado de trabalho e para a necessidade de uma maior divulgação da profissão, por parte do Curso de Biblioteconomia e da Associação Profissional de Bibliotecários de Goiás. Embora seja significativo o número de empresas $(43 \%)$ que possuem nas suas estruturas administrativas, unidades de informação, isto não significa que atribuam à informação um valor estratégico. Nos seus modelos organizacionais, as unidades de informação ocupam, na maioria das vezes, uma posição hierarquicamente inferior. Apesar de ser considerada polêmica nos meios acadêmicos a relação universidade - setor produtivo, a pesquisa aponta para a importância da abertura de canais de negociação entre o Curso de Biblioteconomia e o mercado de trabalho, principalmente no que se refere à importância econômica da informação.

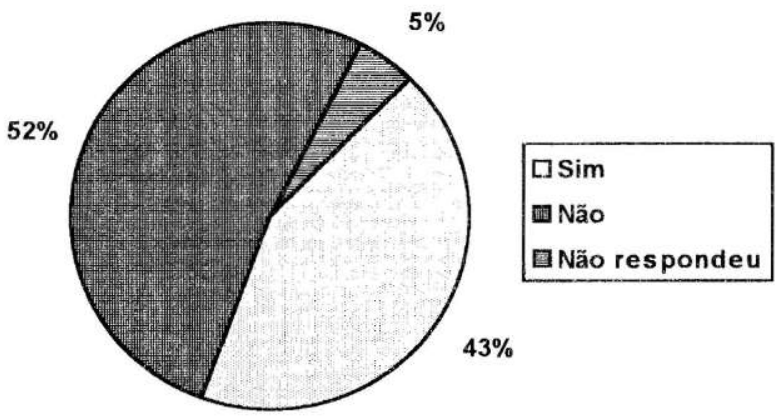

FIGURA 09 - Existência de unidades de informação nas instituições e/ou empresas de Goiânia.

Vale ressaltar que $70 \%$ das instituições e/ou empresas da amostra não possuem bibliotecários nos seus quadros (Fig. 10), o que significa que as unidades de informação existentes nas suas 


\section{4}

estruturas são geridas por profissionais de outras áreas. Apenas $21 \%$ do universo pesquisado contratam profissionais bibliotecários. Cabe ao Conselho Regional de Biblioteconomia $-1{ }^{\text {a }}$ Região proceder a uma fiscalização sistemática do exercício da profissão em Goiânia. Os motivos alegados para a não-contração de bibliotecários, entre outros, é o desconhecimento da importância desse profissional para o alcance dos objetivos institucionais. Consideram que o espaço físico e o acervo são fatores determinantes para a existência de serviços de informação, idéia reforçada pela postura, muitas vezes, tecnicista e, muitas vezes, anacrônica do bibliotecário.

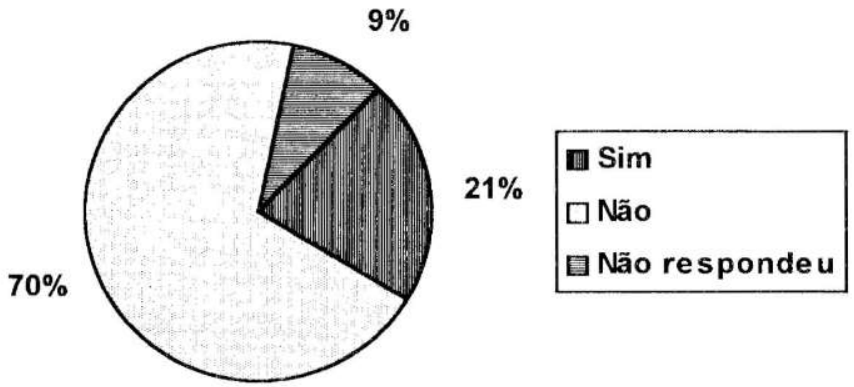

FIGURA 10 - Existência de bibliotecários nas instituições e/ou empresas de Goiânia.

Observou-se uma certa coerência entre a existência do cargo de bibliotecário nas estruturas administrativas das instituições e/ou empresas $(22 \%)$ e a ocupação deste por aquele profissional (Fig. 11). O mesmo não acontece quando se procura estabelecer a relação unidade de informação - bibliotecário, o que reforça a tese de que a existência de unidades de informação (43\% cf. Fig. 09) nem sempre implica a existência do cargo, dando margem à contratação de profissionais de outras áreas. 


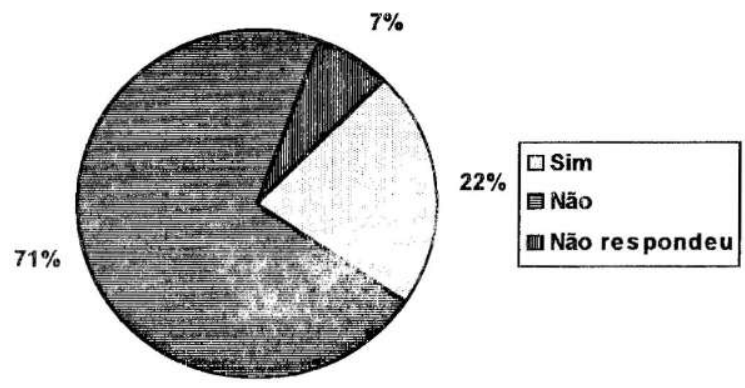

FIGURA $1 /$ - Existência do cargo de bibliotecário nas instituições e/ou empresas de Goiânia.

Observa-se que o item "concurso público" atingiu o maior indice de respostas (49\%). Em segundo lugar (17\%), aparece "currículo e entrevista", o que poderá indicar que a contratação através de concursos públicos é uma prática bastante disseminada em Goiânia, mesmo quando se trata da esfera privada (Fig. 12).

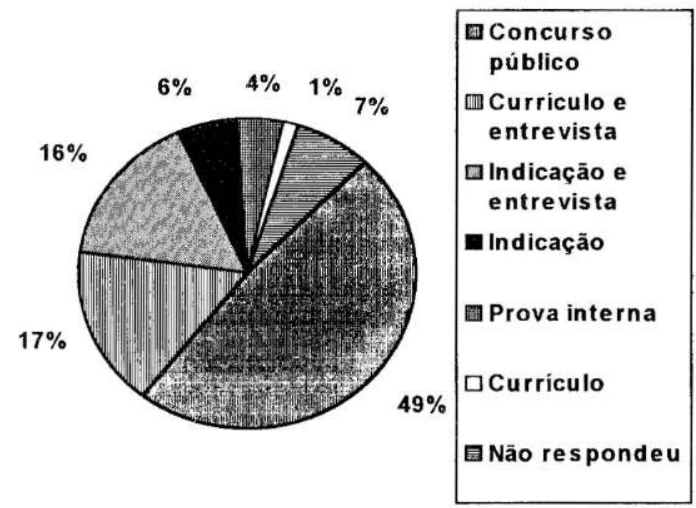

FIGURA 12 - Formas de contratação do bibliotecário pelas instituições e/ou empresas de Goiânia. 
A progressão salarial concedida aos bibliotecários dentro das instituições e/ou empresas de Goiânia obedece ao critério "mérito" $(46 \%)$, o que sugere a adoção de um modelo clientelista dissociado da educação continuada - aqui implícita na progressão por titulação $(2 \%)$ e através de concurso interno $(5 \%)$, índices relativamente inexpressivos. Já o "tempo de serviço" recebeu um percentual significativo-39\% (Fig. 13).
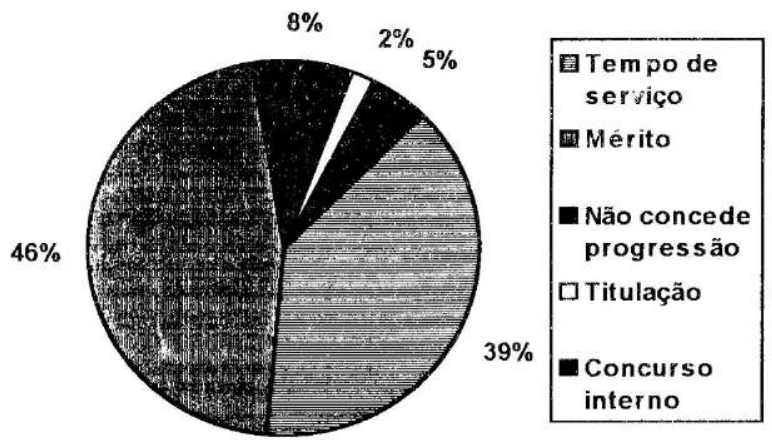

FIGURA 13 - Progressão salarial do profissional bibliotecário nas instituições e/ou empresas de Goiânia.

Embora a maioria das instituições e/ou empresas de Goiânia não tenha respondido ao item "faixa salarial" (40\%), foi possível constatar que $24 \%$ dos responsáveis pelas unidades de informação ganham entre seis e oito salários mínimos. Foi também expressivo o índice dos que ganham até três salários mínimos (16\%). A faixa que se situa acima de onze salários mínimos representa apenas $8 \%$ (Fig. 14).

Vale registrar aqui como referência a faixa de rendimento mensal, de um total de 3.425.699 goianos com dez anos ou mais de idade: $45 \%$ ou 1.541 .564 pessoas declararam ter rendimento mensal entre meio e três salários mínimos ( $\mathrm{R} \$ 56,00$ a $\mathrm{R} \$ 336,00$ em valores atualizados), segundo pesquisa publicada recentemente na media local. Com renda acima de três a cinco mínimos (mais de R\$ 390,00 a R\$ 650,00 ) o percentual é de $6,35 \%$ ou 217.481 
pessoas, enquanto 183.014 , ou $5,34 \%$, declararam rendimento mensal entre mais de cinco a dez salários mínimos (mais de de R \$ $650,00$ a $\mathrm{R} \$ 1.120,00)$. Na faixa de seis a oito salários mínimos encontram-se $24 \%$ dos bibliotecários de Goiânia - o maior índice encontrado -, (Fig. 14), considerando apenas as informações dadas pelos empregadores. É importante registrar que $40 \%$ dos entrevistados não responderam.

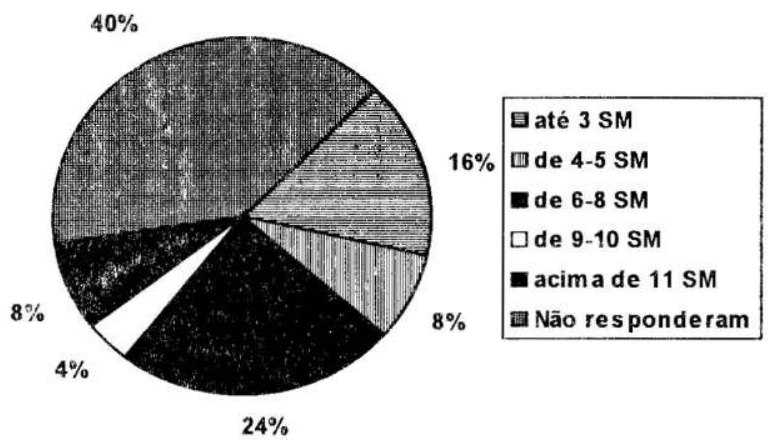

SM Salário mínimo vigente de 1998 (R\$ 120,00)

FIGURA 14 - Faixa salarial dos profissionais responsáveis pelas unidades de informação das instituições e/ou empresas de Goiânia.

Em relação aos serviços de informação demandados pelas instituições e/ou empresas de Goiânia, percebe-se uma grande preocupação pela organização e recuperação de informações especializadas e/ou personalizadas (14\%) e institucionais - memória administrativa - $(24 \%)$. "O intercâmbio de documentos com outros sistemas de informação" foi apontado como uma das necessidades básicas, que se coloca ao lado do processamento técnico das coleções $-13 \%$, respectivamente (Fig. 15). Há um equilíbrio entre as demandas sobre "normalização de publicações", "assessoria em pesquisa", "atendimento aos usuários" e "indexação de artigos de periódicos", o que demonstra uma elevação do nível de sofisticação das necessidades informacionais do setor produtivo de Goiânia. 

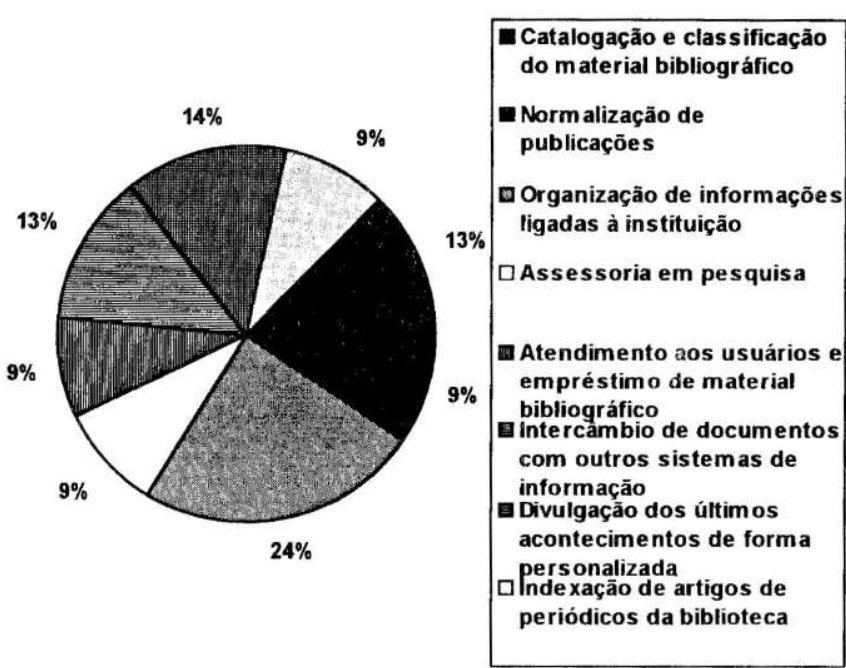

FIGURA 15 - Demanda dos serviços de informação das instituições e/ou empresas de Goiânia.

\section{Conclusões}

Recomenda-se, prioritariamente, uma revisão curricular (já em processo) que contemple as novas necessidades do mercado de trabalho de Goiânia, mas que não perca de vista as demandas nacionais. Goiânia é um mercado em expansão, considerando-se a existência de unidades de informação em $43 \%$ das instituições e/ou empresas entrevistadas (cf. Fig 09). No entanto, $71 \%$ não possuem o cargo de bibliotecário (cf. Fig 11). Este quadro sugere uma intervenção imediata da Associação Profissional dos Bibliotecários de Goiás. Um trabalho de marketing da profissão junto à classe empresarial de Goiânia, mostrando a tendência mundial de elevar o nível de investimentos nos setores de serviços - com destaque para os serviços bibliotecários -, poderia levar a resultados interessantes. 
É importante que o Curso de Biblioteconomia se articule com o setor produtivo local, que parece desconhecer ainda o valor agregado da informação, no sentido de "inaugurar" um trabalho de parceria que traga benefícios recíprocos. Sabe-se que a persistir o atual quadro de descompromisso entre a Academia e a sociedade, a informação perderá, em Goiânia, o seu valor econômico diante da quase impossibilidade de ser utilizada adequadamente pelo setor produtivo e seu alcance social, enquanto instrumento de trais:formação das relações de poder (Echegaray, 1995).

Contudo, para que haja uma mudança cultural na prática bibliotecária, essencialmente elitista, é necessário que haja uma competência técnica aliada à visão crítica da realidade, ou seja, um maior comprometimento com todos os segmentos da "sociedade civil". Vale lembrar aqui o trabalho de Andrade (1989) sobre Centros de Educação Popular, que sinaliza para uma revisão da prática bibliotecária traduzindo as necessidades de informação das classes sociais ditas subalternas.

Os valores sociais são o começo e a destinação da ação educativa porque expressam a própria meta de perfeição da sociedade. Entre estes valores incluem-se: o convívio, a estabilidade econômica, o exercício da criação, o poder da afirmação e autodeterminação (Botelho \& Corte, 1987, p.275).

Em última análise, este trabalho também poderá auxiliar na escolha de temas que possam servir de base para programas de "educação continuada" e para a definição de políticas de pós-graduação (lato e stricto sensu) em Biblioteconomia para a UFG. Aliás, tal contribuição não se volta apenas para a Universidade, mas poderá também direcionar a política da própria Associação Profissional de Bibliotecários de Goiânia.

\section{Abstract}

A report of detailed research concerning academic education of the professional and opportunities of employment for the librarian in Goiânia. The research envolves recently graduated professionals and the business

Comun. inf., v.1, n. 1, p. 194-211, jan./jun. 1998 
institutions and companies who use (or not) computer information services. Besides the model profile described by professional institutions, the authors prepare changes in the educationial curriculum for the professional in (computer) information.

Key words: job market; employment opportunities; professional field of librarians; education.

\section{Referências bibliográficas}

ALMEIDA JÚNIOR, Osvaldo Francisco de. Mercado de trabalho. R. bras. Bibliotecon. Doc. São Paulo, v. 18, n. 1/2, p. 62-77, jan./jun. 1985.

ALMEIDA JÚNIOR, Osvaldo Francisco de. Estudo de caso: mercado e salário. Palavra-chave, São Paulo, n. 4, 1984.

ANDRADE, A. M. C. Um novo texto no contexto da informação popular: os centros de documentação e comunicação. São Paulo, 1989. 202 p. Tese (Doutorado em Comunicação) - Escola de Comunicações e Artes, Universidade de São Paulo.

ASSOCIAÇÃO PAULISTA DE BIBLIOTECÁRIOS. Salário pago ao bibliotecário no Brasil. Palavra-chave, São Paulo, n.4, p.7-9, maio 1984.

BOTASSI, Míriam. Bibliotecária(o): a profissão no feminino e o mercado. Palavra-chave, São Paulo, n. 4, p.3-4, 1984.

BOTELHO, Tânia Mara Guedes, CORTE, Adelaide Ramos. O mercado de trabalho do profissional da informação na área de biblioteconomia na região Centro-Oeste. $R$. Bibliotecon. Brasilia, v. 15, n. 2, p. 249-284, jul./dez. 1987.

CUNHA, Murilo Bastos da. Mercado de trabalho para bibliotecário. In: CONGRESSO BRASILEIRO DE BIBLIOTECO-NOMIA E DOCUMENTAÇÃO, 1977, Porto Alegre. Anais... Porto Alegre: ABRG, 1977.

ECHEGARAY, M. A. A, de. Inovação tecnológica na zona rural de Goiás: estudo em dez municípios. Goiânia, 1995. 280 p. Dissertação (Mestrado em História) - Instituto de Ciências Humanas e Letras, Universidade Federal de Goiás.

GIL, Antônio Carlos. Como elaborar projetos de pesquisa. 3. ed. São Paulo: Atlas, 1994. 159p.

LOPES, Luiz Carlos, RICARTE, Jaqueline, MONAIAR, Laila. O mercado de trabalho para o profissional da informação no Distrito Federal. São Paulo: ANCIB, [199-]. p.35-37.

MARTINS, Myrian Gusmão de. Planejamento bibliotecário para alunos de graduação em biblioteconomia. São Paulo: Pioneira; Brasília: INL, 1980. 166p. il.

MOSTAFA, Solange Puntel, PACHECO, Márcia. Balcão de informaã̧̧es: 0 mercado emergente. s.n.t. 38 p.

Comun. inf., v.1, n. 1, p. 194-211, jan./jun. 1998 
MUELLER, Suzana Pinhciro Machado. Reflexões sobre a formação profissional para biblioteconomia e sua relação com as demais profissões da informação. Trans-in-formação, v. 1, n. 2, p. 175-185, maio/ago. 1989.

OLIVEIRA, Silas Marques de. Identificação das escolas de Biblioteconomia Norte-Americanas mais adequadas para satisfazer as necessidades de desenvolvimento da Biblioteconomia brasileira. São Paulo : ANCIB, [199-]. p. 32-34.

RESER, David W., SCHUNEMAN, Anita P. The academic library job market: a content analysis comparing public and technical services. College \& research libraries. Chicago, Jan. 1992.

ROBREDO, Jaime, CAVALCANTI, Cordélia Robalinho, CUNHA, Murilo Bastos da et al. Tendências observadas no mercado de trabalho dos bibliotecários e técnicos da informação nas bibliotecas especializadas do Distrito Federal e qualificações requeridas. R. Biblioteconomia Brasilia, v. 12, n.2, jul./dez. 1984.

RODRIGUES, Vilma Bernardes. Análise da oferta de cmprego para bibliotecários em bibliotecas de Brasília. Boletim ABDF: Nova Séric. Brasília, v. 5, n.2, p. abr./jun. 1982.

SOUZA, F. das C. de. O ensino de biblioteconomia no contexto brasileiro. Florianópolis: UFSC, 1990. 116p.

SUAIDEN, Emir José. Mercado de trabalho. R. bras. Bibliotecon. Doc. São Paulo, v.14, n.3/4, p. 153-159, jul./dez. 1981.

VAISHNAV, A. A., DEO, V. N. Currente job market and curricula: a pragmatic study. Herald of Library Science, v. 31, n. 3/4, p. 191200, jul./oct. 1992.

VIÁ, Sarah Chucid da. O mercado de trabalho em comunicação e artes e os profissionais formados pela Escola de Comunicação e Artes, nas décadas de 70 e 80. s.n.t. p. 21-27.

Comun. inf., v.1, n. 1, p. 194-211, jan./jun. 1998 